\title{
Numerical investigation of the partitioning phenomenon of carbon dioxide and multiple impurities in deep saline aquifers ${ }^{1}$
}

\author{
Didi $\mathrm{Li}^{\mathrm{a}}$, Xi Jiang ${ }^{\mathrm{b}, *}$ \\ a Department of Safety Science Engineering \& State Key Laboratory of Fire Science, \\ University of Science and Technology of China, Hefei, Anhui 230026, China \\ ${ }^{\mathrm{b}}$ Engineering Department, Lancaster University, Lancaster LA1 4YR, United Kingdom \\ * Corresponding author. E-mail: x.jiang@lancaster.ac.uk; Tel: (+44) 1524592439
}

\section{Highlights}

- The partitioning behaviours of impure $\mathrm{CO}_{2}$ in geological formations are investigated.

- The effects of $\mathrm{N}_{2}, \mathrm{CH}_{4}$ or the mixture of $\mathrm{N}_{2}$ and $\mathrm{CH}_{4}$ are generally similar.

- Less soluble $\mathrm{N}_{2}$ and $\mathrm{CH}_{4}$ enhance gas breakthroughs and the partitioning.

- More soluble species such as $\mathrm{H}_{2} \mathrm{~S}$ dissolves preferentially in the formation brine.

\begin{abstract}
The partitioning behaviours of $\mathrm{CO}_{2}$ with three kinds of common impurities, i.e., $\mathrm{N}_{2}, \mathrm{CH}_{4}$ and $\mathrm{H}_{2} \mathrm{~S}$, in the formation brine are investigated by numerical simulations. The results indicate that the effects of $\mathrm{N}_{2}, \mathrm{CH}_{4}$ or the mixture of $\mathrm{N}_{2}$ and $\mathrm{CH}_{4}$ at the same concentrations are generally similar. The leading gas front is usually made up of less soluble impurities, such as $\mathrm{N}_{2}, \mathrm{CH}_{4}$ or the mixture of $\mathrm{N}_{2}$ and $\mathrm{CH}_{4}$, while more soluble species such as $\mathrm{H}_{2} \mathrm{~S}$ has dissolved preferentially in the formation brine. The separations between different gas species increase as the gas displacement front migrates forwards and contacts more of the aqueous phase. Compared with the partitioning results of the $98 \% \mathrm{CO}_{2}$ and $2 \% \mathrm{H}_{2} \mathrm{~S}$ mixture, the results indicate that the inclusion of less soluble $\mathrm{N}_{2}$ and/or $\mathrm{CH}_{4}$ results in an earlier gas breakthrough and a longer delay between the breakthrough times of $\mathrm{CO}_{2}$ and $\mathrm{H}_{2} \mathrm{~S}$. The early breakthrough of the gas phase is mainly because that the addition of $\mathrm{N}_{2}$ and/or $\mathrm{CH}_{4}$ lowers the viscosity of the gas phase, resulting in a higher gas velocity than that of the $\mathrm{CO}_{2}-\mathrm{H}_{2} \mathrm{~S}$ mixture. Meanwhile, the mobility ratio is higher and the gas mixture contacts the formation brine over a larger area, giving rise to more efficient stripping of the more soluble gas species like $\mathrm{H}_{2} \mathrm{~S}$ and thus larger separations. In the meantime, with the same total concentrations of impurities (12\%), when $2 \%$ $\mathrm{H}_{2} \mathrm{~S}$ is contained in the $\mathrm{CO}_{2}$ streams, gas phase flows slower and thus the breakthrough time is later. Furthermore, the effects on the partitioning phenomenon are weaker with decreasing concentrations of $\mathrm{N}_{2}$ and/or $\mathrm{CH}_{4}$ (from $10 \%$ to $2 \%$ ) with fixed concentrations of other impurity like $\mathrm{H}_{2} \mathrm{~S}$ (2\%). The migration distances and the separations between different gas species change linearly with time on the whole, as confirmed by a simulation in a longer model.
\end{abstract}

Keywords: Partitioning phenomenon; Multiple impurities; Carbon capture and storage; Numerical simulation.

1 This paper was presented at the 7th International Conference on Applied Energy (ICAE2015), March 28-31, 2015, Abu Dhabi, UAE (Original paper title: "An investigation of chromatographic partitioning of $\mathrm{CO}_{2}$ and multiple impurities in geological $\mathrm{CO}_{2}$ sequestration” and Paper No.: 356). 


\section{Introduction}

Since the beginning of the first industrial revolution, there are marked increases in the atmospheric concentrations of greenhouse gases, such as carbon dioxide $\left(\mathrm{CO}_{2}\right)$, methane $\left(\mathrm{CH}_{4}\right)$ and nitrous oxide $\left(\mathrm{N}_{2} \mathrm{O}\right)$. These increases are believed to be the main cause of the global warming [1]. $\mathrm{CO}_{2}$ is the most important greenhouse gas and its emissions generated from fossil fuels and industrial processes account for approximately $78 \%$ of the increase in total greenhouse gas emissions from 1970 to 2010 [2]. Carbon capture and storage (CCS) is one of the most promising carbon abatement options [1-4]. As a matter of fact, geological storage of $\mathrm{CO}_{2}$ streams in deep saline aquifers as well as oil and gas reservoirs is the only method that can be applied on a commercial scale [5]. CCS involves the technologies to capture $\mathrm{CO}_{2}$ produced in power plants and other industrial processes, transport it to suitable geological storage sites, and store it for long-term isolation from the atmosphere [6]. The capture process is the most expensive part of the CCS chain and the purity requirements of the captured $\mathrm{CO}_{2}$ stream play an important role in actual capture costs [7-9]. Some on-going and/or planned CCS operations are considering impure $\mathrm{CO}_{2}$ storage mainly due to economic reasons. However, impurities contained in the $\mathrm{CO}_{2}$ streams are indicated to have adverse effects on both the transport process and storage process.

The presence of impurities in the injected $\mathrm{CO}_{2}$ stream may have an influence on $\mathrm{CO}_{2}$ storage effectiveness and security in geological formations in a variety of ways [7]. Many investigations have put emphasis on the geochemical effects of the impurities contained in the $\mathrm{CO}_{2}$ streams, including the brine acidification effects by co-injected $\mathrm{SO}_{2}, \mathrm{NO}_{2}, \mathrm{or}_{2} \mathrm{~S}$ and the corresponding effects on the porosity and permeability of reservoir and caprock, e.g. [10-15], and the hydrocarbon oxidation by the $\mathrm{O}_{2}$ impurity, e.g. [16-17]. However, it has been suggested that except for the cases of $\mathrm{SO}_{\mathrm{x}}$ and $\mathrm{NO}_{\mathrm{x}}$, the chemical effects of co-injected impurities would be minor [18]. Even for the strong reactive $\mathrm{SO}_{2}$ impurity, it was suggested that the lower $\mathrm{pH}$ caused by $\mathrm{SO}_{2}$ would be buffered by mineral dissolution during the timescale of acidification [19-21]. More importantly, concentrations of the reactive impurities like $\mathrm{SO}_{\mathrm{x}}$ and $\mathrm{NO}_{\mathrm{x}}$ in the captured $\mathrm{CO}_{2}$ streams are usually much lower than those of the non-condensable or inert impurities such as $\mathrm{N}_{2}, \mathrm{CH}_{4}$ and $\mathrm{Ar}$ which do not have any or noticeable geochemical effects in the subsurface. Apart from the possible geochemical effects of certain reactive impurities, the physical properties of impurities could significantly affect the permanence and security of the subsurface sequestration of the impure $\mathrm{CO}_{2}$ streams, especially in the short to medium term. The impurities would lead to changes in physical properties of the $\mathrm{CO}_{2}$ streams, such as density and viscosity, thereby changing buoyancy, interfacial tension as well as other properties, which would affect the migration and dissolution of the $\mathrm{CO}_{2}$ plume [18, 22-24]. It should also be noted that most existing studies give priority to the investigations of the impact of one specific co-injected impurity, such as $\mathrm{SO}_{2}, \mathrm{H}_{2} \mathrm{~S}, \mathrm{~N}_{2}, \mathrm{O}_{2}$ or $\mathrm{CH}_{4}$, etc., while only a few experimental and numerical investigations have examined the effects of impurities in ternary mixtures, e.g. [15, 25-27]. Since practical $\mathrm{CO}_{2}$ streams injected typically contain several kinds of non- $\mathrm{CO}_{2}$ species, it is necessary to investigate the effects of multiple contaminants on the geological storage.

In the past few years, some researchers have focused on the partitioning phenomena of 
impure $\mathrm{CO}_{2}$ storage. The studies were motivated by a report from a gas plant operator in southern Alberta, Canada: after injecting the mixture of $98 \% \mathrm{CO}_{2}$ and $2 \% \mathrm{H}_{2} \mathrm{~S}$ into a depleted gas reservoir, pure $\mathrm{CO}_{2}$ was observed to break through at the producing wells while the breakthrough of the $\mathrm{CO}_{2}-\mathrm{H}_{2} \mathrm{~S}$ mixture was some time later [28, 29]. Both experimental and numerical studies have been performed to study the partitioning behaviour of $\mathrm{CO}_{2}$ and $\mathrm{H}_{2} \mathrm{~S}$ in geological formations [28-31]. The laboratory experiments suggested that the solubility of the contained impurity compared to that of $\mathrm{CO}_{2}$ played the most important role in the partitioning results of $\mathrm{CO}_{2}$ and impurity $[28,29]$. Numerical results implied that various flow parameters, such as relative permeability, dispersion, injected gas composition and flow direction, had influences on the breakthrough time of the gas phase and the separations between the breakthroughs of $\mathrm{CO}_{2}$ and the co-injected impurity [29-31]. Numerical studies have also been carried out to investigate the migration behaviour of $\mathrm{CO}_{2}-\mathrm{N}_{2}$ mixture in the aquifer storage. The results revealed that $\mathrm{CO}_{2}$ was stripped off at the leading displacement front because of the preferential solubility of $\mathrm{CO}_{2}$ compared to $\mathrm{N}_{2}$ [32,33]. Recently, results from a pilot-scale experiment demonstrated that after the co-injection of $\mathrm{CO}_{2}$ and air $\left(\mathrm{N}_{2}\right.$ and $\mathrm{O}_{2}$ mixture), $\mathrm{N}_{2}$ and $\mathrm{O}_{2}$ migrated faster than $\mathrm{CO}_{2}$ in the reservoir and the migration front of the gas phase was made up by $\mathrm{N}_{2}$ and $\mathrm{O}_{2}$ [34].

The investigations of the partitioning phenomenon are useful for understanding the migration behaviour (such as flow, dissolution as well as trapping mechanism) of the injected $\mathrm{CO}_{2}$ mixture in geological formations. More importantly, the chromatographic partitioning process plays an important role in the design of monitoring procedures and the development of emergency plans in case of leakages. For instance, in the case of injected $\mathrm{CO}_{2}$ and $\mathrm{H}_{2} \mathrm{~S}$ mixture in geological formations, if pure $\mathrm{CO}_{2}$ front is detected at the monitoring wells, then it is likely that potential hazardous gas phase containing $\mathrm{H}_{2} \mathrm{~S}$ would show up after some time lag. Similarly, in the case of co-injected $\mathrm{CO}_{2}$ and $\mathrm{N}_{2}$, detection of $\mathrm{N}_{2}$ front may serve as a signal of potential $\mathrm{CO}_{2}$ leakage. However, previous studies mainly focused on the partitioning of $\mathrm{CO}_{2}$ with one specific impurity and to the best of our knowledge, there is only one pilot-scale experiment concerning the partitioning of $\mathrm{CO}_{2}$ with two kinds of impurities $\left(\mathrm{N}_{2}\right.$ and $\left.\mathrm{O}_{2}\right)$ [34]. In the case of $\mathrm{CO}_{2}$ storage with multiple impurities, the composition of the leading plume determines what kind of impurities is to be monitored for $\mathrm{CO}_{2}$ leakage. This work is a first-step investigation on the partitioning phenomena of $\mathrm{CO}_{2}$ with two or three kinds of non- $\mathrm{CO}_{2}$ species. Three types of most common impurities, i.e., $\mathrm{N}_{2}, \mathrm{H}_{2} \mathrm{~S}$ and $\mathrm{CH}_{4}$, were chosen in the present study. Among the three kinds of potential geological formations, including deep saline formations, oil and gas reservoirs and unminable coal beds, deep saline formations were chosen for their largest storage capacity and wide distribution around the world [6].

\section{Physical model}

The $\mathrm{CO}_{2}$ stream is generally injected at depths below $800 \mathrm{~m}$, where the mixture is in a supercritical state (for simplicity, the "supercritical" is referred to as "gas" below) with ambient pressure and temperature higher than 7.38 MPa and $304.13 \mathrm{~K}$, respectively. In the present study, the main fluid properties and model parameters (Table 1) are the same as in the simulations of Bachu et al. [30]. The simulations of the partitioning behaviour of $\mathrm{CO}_{2}$ with two or three kinds of impurities are carried out in the tube model filled with quartz representative 
of the Keg River Formation as that in the experiments of Bachu and Bennion [28]. One-dimensional horizontal radial model is employed and the 24.384-m-long model is divided into 500 equal grid blocks. The compositional reservoir simulator, CMG-GEM [35] is adopted to carry out the simulations. The good match between the numerical results of Bachu et al. [30] and the experimental results of Bachu and Bennion [28] confirms that the CMG-GEM software and the relevant model are capable of capturing the main features of the partitioning process. A horizontal injection well at one boundary is used to represent the displacement rate. At the other boundary, a production well is placed to mimic a constant pressure boundary condition. The dissolution of the gas components in the formation brine is calculated using the general Henry's law [36]:

$$
x_{i}=\frac{f_{i}}{H_{i}}
$$

where, $x_{i}$ is the mole fraction of component $i$ in the aqueous phase; $f_{i}$ is the fugacity of component $i$ in the gas phase, which is calculated using the Peng-Robinson equation of state [37]; The Henry's law constant of each component $\left(H_{i}\right)$ is calculated by Harvey's correlation [38], which takes into account the effects of pressure, temperature and salinity. The correlation by Kestin et al. [39] is adopted to calculate the aqueous phase viscosity while the viscosity of the gas phase is calculated using the Pedersen model [40], which takes into consideration the effects of pressure, temperature and fluid composition. The brine and gas densities are calculated by the Rowe and Chou correlation [41] and the Peng-Robinson EOS respectively. The relative permeability curves for both the gas and aqueous phases are characterized by the Corey correlation [42]. It is worth mentioning here that our simulations employ a different correlation to calculate the Henry's law constants from that in the simulations of Bachu et al. [30]. Moreover, the present study adopts relations of temperature and pressure to calculate the gas viscosity, the brine viscosity as well as the gas and brine density while the corresponding properties in the simulations of Bachu et al. were regarded as constants.

Table 1. Fluid properties and model parameters.

Ten different cases are performed in this study and listed in Table 2. First, the case of $98 \%$ $\mathrm{CO}_{2}+2 \% \mathrm{H}_{2} \mathrm{~S}$ (Case 1) is replicated as the baseline case (or "Case-Base"). Then the migration behaviours of the $\mathrm{CO}_{2}$ plume containing two kinds of impurities are investigated. With the same $\mathrm{CO}_{2}$ mole fraction (88\%), four different impurity combinations are simulated (Cases 2-5): $2 \% \mathrm{H}_{2} \mathrm{~S}+10 \% \mathrm{~N}_{2}, 2 \% \mathrm{H}_{2} \mathrm{~S}+10 \% \mathrm{CH}_{4}, 6 \% \mathrm{~N}_{2}+6 \% \mathrm{CH}_{4}$, and $8 \% \mathrm{~N}_{2}+4 \% \mathrm{CH}_{4}$. After that, two cases of $\mathrm{CO}_{2}$ with all three kinds of non- $\mathrm{CO}_{2}$ species, $88 \% \mathrm{CO}_{2}+2 \% \mathrm{H}_{2} \mathrm{~S}+5 \% \mathrm{~N}_{2}+5 \% \mathrm{CH}_{4}$ and $88 \% \mathrm{CO}_{2}+2 \% \mathrm{H}_{2} \mathrm{~S}+8 \% \mathrm{~N}_{2}+2 \% \mathrm{CH}_{4}$, are studied (Cases 6 and 7). Two more cases of $\mathrm{CO}_{2}-\mathrm{H}_{2} \mathrm{~S}-\mathrm{N}_{2}$ mixtures with $5 \%$ and $2 \% \mathrm{~N}_{2}$ respectively (93\% and $96 \% \mathrm{CO}_{2}$ respectively) are then performed to investigate the effects of impurity concentrations on the partitioning phenomenon (Cases 8 and 9). Finally, since the model length seems small compared to real storage size, the effects of longer model length $(243.84 \mathrm{~m})$, ten times of the present model 
length, are investigated with the $88 \% \mathrm{CO}_{2}+2 \% \mathrm{H}_{2} \mathrm{~S}+10 \% \mathrm{~N}_{2}$ mixture (Case 10). Because the estimated upper limit of $\mathrm{N}_{2}$ concentration in the captured $\mathrm{CO}_{2}$ streams is up to $10 \%$ [43], the mole fraction of $\mathrm{N}_{2}$ in the injected gas mixture is set to be not more than this level. Despite the fact that the possible concentration range of $\mathrm{CH}_{4}$ is generally much lower than that of $\mathrm{N}_{2}$ [43], the maximum $\mathrm{CH}_{4}$ concentration is also chosen to be $10 \%$ so that the effects of $\mathrm{N}_{2}$ and $\mathrm{CH}_{4}$ can be compared and analysed at the same concentration. However, the mole fraction of $\mathrm{CH}_{4}$ in all cases is not more than that of $\mathrm{N}_{2}$. Except for Cases 8 and 9, the mole fraction of $\mathrm{CO}_{2}$ is chosen to be the same (88\%) in the ternary and quaternary mixtures to investigate the effects of different combinations and compositions of impurities on the partitioning phenomenon. The $\mathrm{H}_{2} \mathrm{~S}$ mole fraction is $2 \%$ in all the ternary or quaternary mixtures that contain it to compare the results with the results of $98 \% \mathrm{CO}_{2}$ and $2 \% \mathrm{H}_{2} \mathrm{~S}$ mixture and highlight the effects of the inclusion of other impurities on the partitioning process.

Table 2. List of cases studied.

The present simulations serve as a first step investigation of the partitioning behaviour of $\mathrm{CO}_{2}$ and multiple impurities since practical $\mathrm{CO}_{2}$ streams may contain other kinds of non- $\mathrm{CO}_{2}$ species apart from the chosen three kinds of impurities. To focus on the effects of the impurities as well as to reduce computational time, some assumptions have been used in the physical model and simulations performed. Firstly, all possible thermal effects are neglected and isothermal conditions are adopted in the model. Secondly, at the chosen pressure and temperature, water mole fraction in the gas phase would be less than 2-3\% [44]. In the present study, water vaporization and the relevant side effects such as salt precipitation and reductions in porosity and permeability are not taken into account. Thirdly, capillary effects are negligible because of the high permeability and porosity adopted in the study. Fourthly, the molecular diffusion is not taken into consideration. The results from the simulations are presented and discussed subsequently.

\section{Results}

\subsection{Case-Base}

Fig. 1 shows the gas saturation at five selected times as well as the evolution of the effluent gas phase compositions at the outlet for the $98 \% \mathrm{CO}_{2}$ and $2 \% \mathrm{H}_{2} \mathrm{~S}$ mixture. Cumulative pore volume of production is a constant function of time. As seen in Fig. 1a, the breakthrough time of the gas phase is about 1.3 days, which is consistent with previous experimental results [28] and the numerical results [30]. The migration distances of the gas phase in the present study are somewhat different from the results of Bachu et al. [30] due to several different correlations employed. Nevertheless, the present model could capture the main features of the partitioning behaviour of the $\mathrm{CO}_{2}$ mixture, including the breakthrough time of the gas phase and the delayed breakthrough of $\mathrm{H}_{2} \mathrm{~S}$ at the outlet (Fig. 1b). The separation between the breakthroughs of $\mathrm{CO}_{2}$ and $\mathrm{H}_{2} \mathrm{~S}$ is in rather good agreement with 
previous studies [28-31], especially with the experiment results [28].

Fig. 1. Partitioning results for Case-Base: (a) gas saturation at various times and (b) evolution of the effluent gas compositions at the outlet.

\subsection{Partitioning with two impurities}

Fig. 2 shows the gas position as well as the two phase compositions (mole fractions) at 0.5 day for the $\mathrm{CO}_{2}$ streams containing $2 \% \mathrm{H}_{2} \mathrm{~S}$ and $10 \% \mathrm{~N}_{2}$ (Case 2), and $2 \% \mathrm{H}_{2} \mathrm{~S}$ and $10 \%$ $\mathrm{CH}_{4}$ (Case 3), respectively. It can be seen that the gas front has reached about $12 \mathrm{~m}$ at this time for both cases. The gas saturation at the inlet is smaller than one, which is mainly because that the irreducible water saturation is set to be 0.1 in this study (Table 1). According to the variation of the compositions, gas phase can be divided into three parts. In the first part, from 0 to about $8.8 \mathrm{~m}$, gas phase is made up of $\mathrm{CO}_{2}, \mathrm{H}_{2} \mathrm{~S}$ and $\mathrm{N}_{2}$ or $\mathrm{CH}_{4}$, with basically the same concentrations as in the feed gas. Although $\mathrm{H}_{2} \mathrm{~S}$ mole fraction is only $2 \%$ in the injected $\mathrm{CO}_{2}$ streams, the equilibrium concentration of $\mathrm{H}_{2} \mathrm{~S}$ in the aqueous phase is much higher than that of $\mathrm{N}_{2}$ or $\mathrm{CH}_{4}$ due to its much higher solubility in the formation brine. In the second part (about 8.8-11.3 m), gas phase consists of $\mathrm{CO}_{2}$ and $\mathrm{N}_{2}$ or $\mathrm{CH}_{4}$. This is mainly because that the more soluble $\mathrm{H}_{2} \mathrm{~S}$ has dissolved preferentially in the formation brine and has been stripped away from the $\mathrm{CO}_{2}$ streams. In this range, $\mathrm{CO}_{2}$ concentrations in the gas phase as well as in the aqueous phase increase slightly in response to the disappearance of $\mathrm{H}_{2} \mathrm{~S}$. The concentrations of $\mathrm{N}_{2}$ or $\mathrm{CH}_{4}$ also increase slightly, but not very noticeable. In the third part, i.e., the very leading edge of the gas displacement front, gas phase is composed by pure $\mathrm{N}_{2}$ or pure $\mathrm{CH}_{4}$, while the more soluble $\mathrm{CO}_{2}$ compared to them has been stripped off.

Fig. 2. Position of the gas front and the two phase compositions at 0.5 day. (a) and (b) are for Case 2 while (c) and (d) are for Case 3.

Fig. 3 shows the gas position as well as the two phase compositions at 1.0 day for Cases 2 and 3. Compared with Fig. 2, it is obvious that the separations between different gas species increase as the gas displacement front migrates forwards and contacts more of the aqueous phase. The migration distances of the gas phase as well as the separations between different gas species increase roughly linearly with time. Generally, except for some minor differences, for instance, $\mathrm{CH}_{4}$ concentration in the aqueous phase is higher than that of $\mathrm{N}_{2}$ because of the higher solubility of $\mathrm{CH}_{4}$ than $\mathrm{N}_{2}$, the results of Cases 2 and 3 are similar to each other.

Fig. 3. Position of the gas front and the two phase compositions at 1.0 day. (a) and (b) are for Case 2 while (c) and (d) are for Case 3.

The mobility of a fluid phase $\left(\lambda_{\alpha}\right)$ is represented by the ratio of the relative permeability to 
phase viscosity $[45,46]$,

$$
\lambda_{\alpha}=\frac{k_{r \alpha}}{\mu_{\alpha}}
$$

where, $k_{r \alpha}$ is the relative permeability of phase $\alpha, \mu$ is viscosity. Mobility signifies the flowing capacity of the fluid in the reservoir, which increases with increasing mobility. According to Darcy's law [45], fluid phase velocity is proportional to phase mobility. The mobility ratio $(M)$ is generally defined as the mobility of the displacing phase (gas in the gas/aqueous case) divided by that of the displaced phase, which is the formation brine in this study [45-48],

$$
M=\frac{k_{r g}}{\mu_{g}} / \frac{k_{r b}}{\mu_{b}}=\frac{k_{r g} \mu_{b}}{k_{r b} \mu_{g}}
$$

where, the subscript $g$ stands for gas phase and $b$ for formation brine. For certain displacing and displaced fluids, the mobility ratio has an influence on the degree of flow instability in the displacing process [47]. If $M>1$, it indicates that the flowing capacity of the displacing phase is stronger than that of the displaced phase. In this case, the mobility ratio is regarded as "unfavourable", which means unstable displacements of the aqueous phase by the gas phase and poor sweep efficiency. The displacing phase may pass through the displaced phase in the form of "fingers" or even break through (viscous fingering), which means a larger two-phase region. Meanwhile, in a favourable mobility ratio $(M<1)$ situation, the fingering phenomenon is weakened and the displacements are in piston-like movements, which means that the leading displacing front is stable while the two-phase region is smaller.

Fig. 4 shows the variations of the gas phase velocity and the mobility ratio with distances at 0.5 day and 1.0 day for Cases 1-3. It can be seen that the trends of both the gas velocity and the mobility ratio are in accordance with that of the corresponding gas saturation (Figs. 2 and 3 ), decreasing with increasing distances. Compared to the baseline case of $98 \% \mathrm{CO}_{2}$ and $2 \%$ $\mathrm{H}_{2} \mathrm{~S}$, the inclusion of $10 \% \mathrm{~N}_{2}$ or $10 \% \mathrm{CH}_{4}$ increases the velocity of the gas phase as well as the mobility ratio at the leading gas displacement front. At the very leading edge of the displacing front, where the gas phase is made up of pure $\mathrm{N}_{2}$ or pure $\mathrm{CH}_{4}$, both the velocity of the gas phase and the mobility ratio remain constant values. Furthermore, the mobility ratios are smaller than unity at the leading gas displacement front, which indicates that the displacements at the leading gas front are rather stable. Except that the constant values at the leading gas displacement front are different mainly due to different viscosities of $\mathrm{N}_{2}$ and $\mathrm{CH}_{4}$, the gas phase velocity and mobility ratio of the $10 \% \mathrm{~N}_{2}$ and $10 \% \mathrm{CH}_{4}$ cases are very similar to each other.

Fig. 4. The variations of (a) gas phase velocity and (b) mobility ratio with distances.

Fig. 5 shows the time evolution of the effluent gas phase compositions at the outlet of the tube model, which denotes the potential sequences of the gas species to break through if leakage occurs at $24.384 \mathrm{~m}$. Compared with the baseline case of $98 \% \mathrm{CO}_{2}$ and $2 \% \mathrm{H}_{2} \mathrm{~S}$, the 
inclusion of the $10 \% \mathrm{~N}_{2}$ or $10 \% \mathrm{CH}_{4}$ impurity (Case 2 or 3 ) leads to an earlier gas breakthrough. The breakthrough time of the gas phase in Cases 2 and 3 is almost the same, about 1.0 day, while the gas breakthrough time in Case-Base is about 1.2 days. Furthermore, the breakthrough time of $\mathrm{CO}_{2}$ in Cases 2 and 3 (about 1.11 days and 1.12 days respectively) is earlier than that (1.20 days) in Case-Base. On the contrary, the breakthrough time of $\mathrm{H}_{2} \mathrm{~S}$ in Cases 2 and 3 (about 1.45 days and 1.425 days respectively) is slightly later than that (about 1.41 days) in Case-Base. It implies that there is a longer delay between the breakthrough times of $\mathrm{CO}_{2}$ and $\mathrm{H}_{2} \mathrm{~S}$ because of the inclusion of the $10 \% \mathrm{~N}_{2}$ or $\mathrm{CH}_{4}$.

Fig. 5. Time evolution of the effluent gas compositions at the outlet for (a) Cases 1 and 2 and (b) Cases 1 and 3.

Figs. 6 and 7 show the gas position as well as the two phase compositions for the two cases of $\mathrm{CO}_{2}-\mathrm{N}_{2}-\mathrm{CH}_{4}$ mixture (Cases 4 and 5) at 0.5 day and 1.0 day, respectively. Compared with Cases 2 and 3, it can be seen that the migration distances of the gas phase are a little longer in these two cases that do not contain the $2 \% \mathrm{H}_{2} \mathrm{~S}$. For instance, the migration distance of the gas front is about $12.3 \mathrm{~m}$ in Cases 4 and 5 at 0.5 day while it is about $12.0 \mathrm{~m}$ in Cases 2 and 3. At 1.0 day, the gas saturation at the outlet in Cases 4 and 5 is greater than zero. Accordingly, the mole fractions of $\mathrm{N}_{2}$ and $\mathrm{CH}_{4}$ in the gas phase and the aqueous phase do not turn into 0 at this point. It indicates that the breakthrough time of the gas phase is earlier than 1.0 day, particularly, earlier than the breakthrough times of the above cases that include $2 \%$ $\mathrm{H}_{2} \mathrm{~S}$ impurity (approximately 1.0 day in Cases 2 and 3).

Fig. 8 compares the variations of the gas phase velocity and the mobility ratio among Cases 2, 4 and 5. Different compositions of $\mathrm{N}_{2}$ and $\mathrm{CH}_{4}\left(6 \% \mathrm{~N}_{2}\right.$ and $6 \% \mathrm{CH}_{4}$ vs $8 \% \mathrm{~N}_{2}$ and $4 \%$ $\mathrm{CH}_{4}$ ) do not seem to cause noticeable change in the velocity of the gas phase and mobility ratio. The time evolution of the effluent gas phase compositions at the outlet as shown in Fig. 9 confirms that the breakthrough times of the gas phase for the two cases of $\mathrm{CO}_{2}-\mathrm{N}_{2}-\mathrm{CH}_{4}$ mixture are actually before 1.0 day and that $\mathrm{N}_{2}$ and $\mathrm{CH}_{4}$ break through at the same time at the outlet in Cases 4 and 5.

According to the variations of the compositions, gas phase in Cases 4 and 5 can be divided into two parts. In the first part, gas phase is made up of $\mathrm{CO}_{2}, \mathrm{~N}_{2}$ and $\mathrm{CH}_{4}$, with basically the same concentrations as in the feed gas. In the second part, i.e., the leading edge of the gas displacement front, gas phase is made up of the $\mathrm{N}_{2}$ and $\mathrm{CH}_{4}$ mixture. The co-existence of $\mathrm{N}_{2}$ and $\mathrm{CH}_{4}$ at the leading gas front is mainly because that the solubilities of these two species are comparable and neither of them has been stripped off at the leading gas front. However, since $\mathrm{N}_{2}$ is less soluble than $\mathrm{CH}_{4}$ in the aqueous phase, $\mathrm{N}_{2}$ concentration increases while $\mathrm{CH}_{4}$ concentration decreases at the very leading front of gas displacement, even when the concentrations of $\mathrm{N}_{2}$ and $\mathrm{CH}_{4}$ are the same in the feed gas (Case 4: 6\% $\mathrm{N}_{2}$ and 6\% $\mathrm{CH}_{4}$ ). Generally, except that the two phase concentrations of $\mathrm{N}_{2}$ and $\mathrm{CH}_{4}$ are different, the results of these two cases of $\mathrm{CO}_{2}-\mathrm{N}_{2}-\mathrm{CH}_{4}$ mixture, including the migration distances of the gas phase and the separations between different gas species, are similar to each other. 
Fig. 6. Position of the gas front and the two phase compositions at 0.5 day. (a) and (b) are for Case 4 while (c) and (d) are for Case 5.

Fig. 7. Position of the gas front and the two phase compositions at 1.0 day. (a) and (b) are for Case 4 while (c) and (d) are for Case 5.

Fig. 8. The variations of (a) gas phase velocity and (b) mobility ratio with distances.

Fig. 9. Time evolution of the effluent gas compositions at the outlet for (a) Cases 1 and 4 and (b) Cases 1 and 5.

\subsection{Partitioning with three impurities}

Figs. 10 and 11 show the gas position as well as the two phase compositions for the two cases of $\mathrm{CO}_{2}-\mathrm{H}_{2} \mathrm{~S}-\mathrm{N}_{2}-\mathrm{CH}_{4}$ mixture (Cases 6 and 7) at 0.5 day and 1.0 day, respectively. With the same total concentrations (10\%), different compositions of the $\mathrm{N}_{2}$ and $\mathrm{CH}_{4}$ mixture $\left(5 \% \mathrm{~N}_{2}\right.$ and $5 \% \mathrm{CH}_{4}$ vs $8 \% \mathrm{~N}_{2}$ and $2 \% \mathrm{CH}_{4}$ ) barely have an effect on the partitioning results with other species. As shown in Fig. 12a, the gas phase velocity and the mobility ratio hardly change in response to different $\mathrm{N}_{2}$ and $\mathrm{CH}_{4}$ compositions in Cases 6 and 7. Generally, Cases 4-7 share similar patterns and the leading edge of the gas displacement front is made up of the $\mathrm{N}_{2}$ and $\mathrm{CH}_{4}$ mixture. However, the inclusion of $2 \% \mathrm{H}_{2} \mathrm{~S}$ and the corresponding decreasing concentrations of $\mathrm{N}_{2}$ and/or $\mathrm{CH}_{4}$ in Cases 6 and 7 lead to slightly lower gas phase velocity (Fig. 12a) and thus shorter migration distances of the gas phase, compared to Cases 4 and 5. At 1.0 day, the migration distance of the gas plume is about $24 \mathrm{~m}$ in Cases 6 and 7 while gas phase has broken through at the outlet of the 24.384-m-long tube in Cases 4 and 5 (Figs. 7 and 9).

In the meantime, comparing Cases 6 and 7 with Cases 2 and 3, it can be seen that except for the co-existence of $\mathrm{N}_{2}$ and $\mathrm{CH}_{4}$ in Cases 6 and 7, the general characteristics of these four cases are basically the same, including the migration distances of the gas phase, the migration distances of $\mathrm{H}_{2} \mathrm{~S}$ and $\mathrm{CO}_{2}$, as well as the separations between different gas species. Fig. 12b compares the mobility ratios of the four cases. It is obvious that the mobility ratios of Cases 2, 3, 6 and 7 are similar with each other, except the constant values at the very leading front of gas displacement, which is due to different gas compositions and concentrations. Consequently, the breakthrough times of the gas phase, and the time intervals between the breakthroughs of different gas species are also very similar (Figs. 5 and 13).

Fig. 10. Position of the gas front and the two phase compositions at 0.5 day. (a) and (b) are Case 7 while (c) and (d) are for Case 8.

Fig. 11. Position of the gas front and the two phase compositions at 1.0 day. (a) and (b) are 
Case 6 while (c) and (d) are for Case 7.

Fig. 12. The variations of (a) gas phase velocity and (b) mobility ratio with distances.

Fig. 13. Time evolution of the effluent gas compositions at the outlet for (a) Cases 1 and 6 and (b) Cases 1 and 7.

\subsection{The effects of different concentrations of impurity}

The effects of different concentrations of $\mathrm{H}_{2} \mathrm{~S}$ on the partitioning phenomenon have been investigated by other researchers [28-31]. From the above-mentioned results, it can be seen that the effects of $\mathrm{N}_{2}, \mathrm{CH}_{4}$ or the mixture $\mathrm{N}_{2}$ and $\mathrm{CH}_{4}$ at the same concentrations on the partitioning phenomenon are similar. Thus, the effects of different concentrations of $\mathrm{N}_{2}$ and/or $\mathrm{CH}_{4}$ impurity are represented by the effects of different $\mathrm{N}_{2}$ concentrations in this study. Fig. 14 shows the gas position as well as the gas phase compositions at 0.5 day and 1.0 day for cases containing 5\% $\mathrm{N}_{2}$ and 2\% $\mathrm{N}_{2}$ (Cases 8 and 9), respectively. Compared with the $10 \% \mathrm{~N}_{2}$ case (Fig. 2a and 3a), it can be seen that the migration distance of the gas phase decreases with decreasing $\mathrm{N}_{2}$ concentrations in the injected $\mathrm{CO}_{2}$ mixtures. The leading edge of the gas phase reached about $23.82 \mathrm{~m}$ for the case with $10 \% \mathrm{~N}_{2}$ (Case 1) at 1.0 day, while the figures for the $5 \% \mathrm{~N}_{2}$ and $2 \% \mathrm{~N}_{2}$ cases are $22.36 \mathrm{~m}$ and $21.14 \mathrm{~m}$ respectively. This is because the gas phase velocity decreases with decreasing $\mathrm{N}_{2}$ concentrations, as shown in Fig. 15a.

Comparing Figs. 2a, 3a and 14, it can be seen that the migration distance of $\mathrm{CO}_{2}$ increases with decreasing $\mathrm{N}_{2}$ concentrations. For instance, $\mathrm{CO}_{2}$ has arrived at about $22.17 \mathrm{~m}$ in the $10 \%$ $\mathrm{N}_{2}$ case at 1.0 day, while it only migrates $21.62 \mathrm{~m}$ and $21.09 \mathrm{~m}$ for the $5 \% \mathrm{~N}_{2}$ and $2 \% \mathrm{~N}_{2}$ case. Meanwhile, the migration distance of $\mathrm{H}_{2} \mathrm{~S}$ increases slightly with decreasing $\mathrm{N}_{2}$ concentrations. As a result, the separation between $\mathrm{H}_{2} \mathrm{~S}$ and $\mathrm{CO}_{2}$ decreases with decreasing $\mathrm{N}_{2}$ concentrations. Furthermore, the range of the leading displacement front consisting of pure $\mathrm{N}_{2}$, that is, the separation between $\mathrm{CO}_{2}$ and $\mathrm{N}_{2}$ also decreases with decreasing $\mathrm{N}_{2}$ concentrations.

Fig. 14. Position of the gas front and the gas phase compositions for (a) Case 8 at 0.5 day, (b) Case 9 at 0.5 day, (c) Case 8 at 1.0 day and (d) Case 9 at 1.0 day.

Fig. 15. The variations of (a) gas phase velocity and (b) mobility ratio with distances.

Fig. 16 shows the time evolution of the effluent gas phase compositions at the outlet for Cases 8 and 9, respectively. The breakthrough time of the gas phase increases with decreasing $\mathrm{N}_{2}$ concentrations in the $\mathrm{CO}_{2}-\mathrm{H}_{2} \mathrm{~S}-\mathrm{N}_{2}$ mixture, from about 1.0 day in the $10 \% \mathrm{~N}_{2}$ case to about 1.15 days in the $2 \% \mathrm{~N}_{2}$ case. These profiles also demonstrate that there are decreasing separations between more soluble species and less soluble species with decreasing $\mathrm{N}_{2}$ 
concentrations.

Fig. 16. Time evolution of the effluent gas compositions at the outlet for (a) Cases 1 and 8 and (b) Cases 1 and 9.

\subsection{Longer model length}

The model length of the preceding simulations is $24.384 \mathrm{~m}$, which is very small compared to the migration distance in actual storage reservoirs, especially in long-term storage. Furthermore, the boundary conditions of the small-size model may have an impact on the simulation results. To evaluate the effects of the limited size of the model, a model with longer length of $243.84 \mathrm{~m}$ is chosen to simulate the case of $88 \% \mathrm{CO}_{2}+2 \% \mathrm{H}_{2} \mathrm{~S}+10 \% \mathrm{~N}_{2}$ (same composition as in Case 2). Except for the length of the model and the simulation time, all the other parameters are the same as in the 24.384-m-long model. Fig. 17 shows the position of the gas front and the two phase compositions for the $\mathrm{CO}_{2}-\mathrm{N}_{2}-\mathrm{H}_{2} \mathrm{~S}$ mixture at 5 days and 10 days, respectively. Fig. 18 shows the time evolution of the effluent gas compositions at the outlet. Generally, these profiles share the same trends as the corresponding profiles in previous small-size model. The migration distances of the gas phase and the separations between different gas species are almost ten times of those in Figs. 2 and 3. The breakthrough time of the gas phase and the time intervals between the breakthroughs of different gas species are also approximately tenfold of those in Case 2. The results of the longer model confirm that the migration distances of the gas phase and separations between different gas species increase roughly linearly with time.

Fig. 17. Position of the gas front and two phase compositions for $88 \% \mathrm{CO}_{2}+2 \% \mathrm{H}_{2} \mathrm{~S}+10 \%$ $\mathrm{N}_{2}$. (a) and (b) are at 5 days while (c) and (d) are at 10 days.

Fig. 18. Time evolution of the effluent gas compositions at the outlet of the 243.84 m-model for $88 \% \mathrm{CO}_{2}+2 \% \mathrm{H}_{2} \mathrm{~S}+10 \% \mathrm{~N}_{2}$.

\section{Discussions}

After injected in geological formations for storage, $\mathrm{CO}_{2}$ and the co-injected impurities are likely to partition at the leading gas displacement front that advances through the aqueous phase. More soluble gas species would dissolve preferentially in the formation brine and be stripped off at the leading gas front. As for the three common impurities chosen in the present study, $\mathrm{H}_{2} \mathrm{~S}$ is more soluble than $\mathrm{CO}_{2}$, while the solubility of $\mathrm{N}_{2}$ and $\mathrm{CH}_{4}$ is comparable and lower than that of $\mathrm{CO}_{2}$. The leading gas front is made up of less soluble $\mathrm{N}_{2}, \mathrm{CH}_{4}$ or the mixture of $\mathrm{N}_{2}$ and $\mathrm{CH}_{4}$. It implies that when the injected $\mathrm{CO}_{2}$ streams contain $\mathrm{N}_{2}$ and/or $\mathrm{CH}_{4}, \mathrm{~N}_{2}$ and/or $\mathrm{CH}_{4}$ would break through ahead of $\mathrm{CO}_{2}$. 
The dominant factor in the mobility ratio correlation is the viscosity ratio between the aqueous and the gas phase. Since the viscosity of both $\mathrm{N}_{2}$ and $\mathrm{CH}_{4}$ is smaller than that of $\mathrm{CO}_{2}$, the inclusion of $\mathrm{N}_{2}$ and/or $\mathrm{CH}_{4}$ leads to lower gas phase viscosity and thus higher mobility ratio (for example, Fig. 4b), resulting in more unstable displacements of the aqueous phase by the gas phase and longer two-phase regions. Since the dissolution of gas species takes place in a longer two-phase region, gas species with higher solubility such as $\mathrm{H}_{2} \mathrm{~S}$ compared to $\mathrm{N}_{2}$ and/or $\mathrm{CH}_{4}$ are stripped off more effectively at the leading edge of the gas displacement front, leading to larger separations between the more soluble components and the less soluble components. Accordingly, the time lags between the breakthroughs of different species are larger (e.g. Case 2 or 3 vs Case 1). The $\mathrm{CO}_{2}$ plumes containing $\mathrm{N}_{2}$ and/or $\mathrm{CH}_{4}$ also flow faster and reach the outlet earlier, i.e., the breakthrough time is earlier than that for those do not contain $\mathrm{N}_{2}$ and/or $\mathrm{CH}_{4}$ (e.g. Fig. 5). On the contrary, the viscosity of $\mathrm{H}_{2} \mathrm{~S}$ is larger than that of $\mathrm{CO}_{2}$. As a result, the inclusion of $\mathrm{H}_{2} \mathrm{~S}$ impurity leads to lower mobility ratio and lower gas phase velocity. For the injected gas mixtures containing the same total impurity concentration (12\%), the combinations of $\mathrm{N}_{2}$ and $\mathrm{CH}_{4}$ impurities without $\mathrm{H}_{2} \mathrm{~S}$ lead to the fastest flowing and thus the earliest breakthrough of the gas phase. With decreasing $\mathrm{N}_{2}$ or $\mathrm{CH}_{4}$ concentrations, however, both the mobility ratio and the gas phase velocity are lower, leading to weaker partitioning processes (Cases 8 and 9).

The simulation results of the $\mathrm{CO}_{2}$ streams containing the same total concentrations of $\mathrm{N}_{2}$, $\mathrm{CH}_{4}$ or even $\mathrm{N}_{2}$ and $\mathrm{CH}_{4}$ mixture are similar to each other, including the migration distances of the gas phase, the separations of the migration distances between different gas species, the breakthrough times of the gas phase, and the time intervals between the breakthrough times of different gas species (Cases 2, 3, 6 and 7). Different compositions of the $\mathrm{N}_{2}$ and $\mathrm{CH}_{4}$ mixture (for instance, Case 4: $6 \% \mathrm{~N}_{2}+6 \% \mathrm{CH}_{4}$ vs Case 5: $8 \% \mathrm{~N}_{2}+4 \% \mathrm{CH}_{4}$ ) are not likely to change the main features of the partitioning process. It seems that the effects of the $\mathrm{N}_{2}$ and $\mathrm{CH}_{4}$ mixture on the partitioning phenomenon can be represented by that of pure $\mathrm{N}_{2}$ or pure $\mathrm{CH}_{4}$ at the same concentrations. However, it should be noted that since $\mathrm{N}_{2}$ is less soluble than $\mathrm{CH}_{4}$ in the formation brine, $\mathrm{N}_{2}$ concentration is higher than $\mathrm{CH}_{4}$ concentration in the effluent gas phase, even when their concentrations are the same in the feed gas (Cases 4 and 6).

The results of the present study may be applied to the monitoring of $\mathrm{CO}_{2}$ movement in the subsurface and near-surface leakage. In this sense, the co-injected impurities serve as tracers. Actually, tracer methods have already been used to monitor the migration and distribution of the injected $\mathrm{CO}_{2}$ plume and track potential $\mathrm{CO}_{2}$ leakage. For example, noble gases such as $\mathrm{He}$, $\mathrm{Ne}$ and Ar, e.g. [49-51] and perfluorocarbon tracers [52-54] have been used as to identify $\mathrm{CO}_{2}$ migration or to monitor leakage. The tracers were normally in very small amounts and were injected or added intentionally for short-periods monitoring while sufficient amount of these artificial tracers for large-scale projects might be cost-prohibitive [54]. Stable carbon isotopes have been regarded as suitable tracers to assess $\mathrm{CO}_{2}$ migration and detect potential leakage, especially at large injection sites, e.g. [55-57]. However, this method requires the injected $\mathrm{CO}_{2}$ to be isotopically distinct from background sources of $\mathrm{CO}_{2}$ to be effective [57]. The work presented here addresses the issue of co-injected impurities. The results indicate that if leakage occurs after $\mathrm{CO}_{2}$ streams containing $\mathrm{N}_{2}$ and/or $\mathrm{CH}_{4}$ are injected, $\mathrm{N}_{2}$ and/or $\mathrm{CH}_{4}$ would show up in the surface prior $\mathrm{CO}_{2}$ leakage. The detection of these species can be served as a warning of $\mathrm{CO}_{2}$ leakage that would occur after a certain time. Furthermore, it can be expected that if 
leakage occurs after longer migration of the $\mathrm{CO}_{2}$ plume in long-term storage, there will be larger time intervals between the breakthroughs of different gas species. Some saline aquifers may have pre-existing $\mathrm{CH}_{4}$, which would have an adverse effect on its use of tracers. Since $\mathrm{N}_{2}$ is absent in most reservoirs and less soluble than $\mathrm{CH}_{4}$, it seems that $\mathrm{N}_{2}$ is a better choice as a than $\mathrm{CH}_{4}$.

\section{Conclusions and future work}

To realize large-scale implementation of $\mathrm{CO}_{2}$ geological storage, it is necessary to determine the types and concentrations of impurities allowed in the $\mathrm{CO}_{2}$ stream from both economic and regulatory perspectives. A series of numerical simulations are carried out to investigate the partitioning phenomena of $\mathrm{CO}_{2}$ with two or three kinds of most common impurities, $\mathrm{H}_{2} \mathrm{~S}, \mathrm{~N}_{2}$ and $\mathrm{CH}_{4}$. Generally, the results of $\mathrm{CO}_{2}$ streams containing $\mathrm{N}_{2}, \mathrm{CH}_{4}$ as well as the mixture of $\mathrm{N}_{2}$ and $\mathrm{CH}_{4}$ at the same concentrations are similar to each other. The gas phase flows faster and the breakthrough time of the gas phase is earlier when $\mathrm{N}_{2}$ and/or $\mathrm{CH}_{4}$ impurities are co-injected with $\mathrm{CO}_{2}$, especially when the concentrations of these impurities are higher. On the contrary, the inclusion of the $\mathrm{H}_{2} \mathrm{~S}$ impurity is likely to lead to slower migration of the gas phase and delayed breakthrough time of the gas phase.

Although the model size used in the present study is small, test on a larger size model implies that the broad behaviours identified from the small size simulations are valid and may be used to predict the long-distance migration and partitioning phenomenon of the gas plume in long-term storage. The investigations of the partitioning phenomenon are helpful for understanding the migration process of the $\mathrm{CO}_{2}$ plume with multiple impurities. The simulation results obtained in this study may provide references for devising monitoring procedures of possible leakage and developing emergency strategies. For instance, the concentrations of $\mathrm{N}_{2}$ and/or $\mathrm{CH}_{4}$ should be monitored in addition to the monitoring of $\mathrm{CO}_{2}$ concentrations. The detection of sharply increasing levels of $\mathrm{N}_{2}, \mathrm{CH}_{4}$ or the mixture of $\mathrm{N}_{2}$ and $\mathrm{CH}_{4}$ can be seen as a warning of $\mathrm{CO}_{2}$ leakage.

In this study, molecular diffusion has been neglected while it may play a part in the partitioning phenomena. In the future, the migration of injected $\mathrm{CO}_{2}$ with multiple impurities taking into account molecular diffusion, reservoir heterogeneity as well as the effects of dimensionality will be investigated. Some potential storage sites may contain pre-existing impurities such as $\mathrm{H}_{2} \mathrm{~S}$ and/or $\mathrm{CH}_{4}$, whose effects on the partitioning phenomena will also be considered.

\section{Acknowledgement}

This work was supported by the Fundamental Research Funds for the Central Universities (no.WK2320000034). 


\section{References}

[1] IPCC (Intergovernmental Panel on Climate Change). Climate change 2007: The physical science basis. Contribution of Working Group I to the Fourth Assessment Report of the Intergovernmental Panel on Climate Change. IPCC Secretariat, Geneva, Switzerland, 2007.

[2] IPCC (Intergovernmental Panel on Climate Change). Climate change 2014: Mitigation of climate change. Working Group III Contribution to the Fifth Assessment Report of the Intergovernmental Panel on Climate Change. Cambridge University Press, Cambridge, UK, New York, NY, USA, 2014.

[3] Bachu S. $\mathrm{CO}_{2}$ storage in geological media: role, means, status and barriers to deployment. Prog Energy Combust Sci 2008;34:254-73.

[4] Jiang X. A review of physical modelling and numerical simulation of long-term geological storage of $\mathrm{CO}_{2}$. Appl Energy 2011;88(11):3557-66.

[5] Rackley, SA. Carbon capture and storage, $1^{\text {st }}$ Edition. Butterworth-Heinemann, 2009.

[6] IPCC (Intergovernmental Panel on Climate Change). In: Metz B, Davidson O, de Coninck H, Loos M, Meyer LA, editors. IPCC special report: Carbon dioxide capture and storage. New York: Cambridge University Press, 2005.

[7] IEAGHG. Effects of impurities on geological storage of $\mathrm{CO}_{2}$. Report 2011/04, June, 2011.

[8] Knauss KG, Johnson JW, Steefel CI. Evaluation of the impact of $\mathrm{CO}_{2}$, co-contaminant gas, aqueous fluid and reservoir rock interactions on the geologic sequestration of $\mathrm{CO}_{2}$. Chem Geol 2005;217:339-50.

[9] Ji XY, Zhu C. Predicting possible effects of $\mathrm{H}_{2} \mathrm{~S}$ impurity on $\mathrm{CO}_{2}$ transportation and geological storage. Environ Sci Technol 2013;47:55-62.

[10] Knauss KG, Johnson JW, Steefel CI. Evaluation of the impact of $\mathrm{CO}_{2}$, co-contaminant gas, aqueous fluid and reservoir rock interactions on the geologic sequestration of $\mathrm{CO}_{2}$. Chem Geol 2005;217:339-50.

[11] Xu TF, Apps J A, Pruess K, Yamamoto H. Numerical modeling of injection and mineral trapping of $\mathrm{CO}_{2}$ with $\mathrm{H}_{2} \mathrm{~S}$ and $\mathrm{SO}_{2}$ in a sandstone formation. Chem Geol 2007;242:319-46.

[12] Bacon DH, Sass B M, Bhargava M, Sminchak J, Gupta N. Reactive transport modeling of $\mathrm{CO}_{2}$ and $\mathrm{SO}_{2}$ injection into deep saline formations and their effect on the hydraulic properties of host rocks. Energy Procedia 2009;1:3283-90.

[13] Bacon DH, Murphy EM. Managing chemistry underground: is co-sequestration an option in selected formations? Energy Procedia 2011;4:4457-64.

[14] Wilke FDH, Vásquez M, Wiersberg T, Naumann R, Erzinger J. On the interaction of pure and impure supercritical $\mathrm{CO}_{2}$ with rock forming minerals in saline aquifers: An experimental geochemical approach. Appl Geochem 2012;27:1615-22.

[15] Bolourinejad P, Herber R. Experimental investigation of porosity and permeability 
variations in reservoirs and caprock following co-injection of sulfur dioxide and hydrogen sulfide with carbon dioxide. J Petrol Sci Eng 2015;129:137-44.

[16] Pacini-Petitjean C, Morajkar P, Burkle-Vitzthum V, Randi A, Lorgeoux C, Morel D. Oxidation of $\mathrm{n}$ - Alkane ( $\mathrm{n}-\mathrm{C} 8 \mathrm{H} 18)$ under reservoir conditions, in context of gas mixture injection $\left(\mathrm{CO}_{2} / \mathrm{O}_{2}\right)$ : Construction of a kinetic model. Energ Fuel 2015;29:1913-22.

[17] Pacini-Petitjean C, Faure P, Burkle-Vitzthum V, Randi A, Pironon J. Oxidation of $\mathrm{N}$-hexadecane and crude oil in response to injection of a $\mathrm{CO}_{2} / \mathrm{O}_{2}$ mixture under depleted reservoir conditions: Experimental and kinetic modeling preliminary results. Int $\mathrm{J}$ Greenhouse Gas Control 2015;35:110-9.

[18] Talman S. Subsurface geochemical fate and effects of impurities contained in a $\mathrm{CO}_{2}$ stream injected into a deep saline aquifer: What is known. Int J Greenhouse Gas Control 2015;40:267-91.

[19] Ellis BR, Crandell LE, Peters CA. Limitations for brine acidification due to $\mathrm{SO}_{2}$ co-injection in geologic carbon sequestration. Int $\mathrm{J}$ Greenhouse Gas Control 2010;4:575-82.

[20] Pearce JK, Law ACK, Dawson GKW, Golding SD. $\mathrm{SO}_{2}-\mathrm{CO}_{2}$ and pure $\mathrm{CO}_{2}$ reactivity of ferroan carbonates at carbon storage conditions. Chem Geol 2015;41:112-24.

[21] Pearce JK, Kirste DK, Dawson GKW, Farquhar SM, Biddle D, Golding SD, et al. $\mathrm{SO}_{2}$ impurity impacts on experimental and simulated $\mathrm{CO}_{2}$-water-reservoir rock reactions at carbon storage conditions. Chem Geol 2015;399:65-86.

[22] Pau GSH, Bell JB, Pruess K, Almgren AS, Lijewski MJ, Zhang K. High-resolution simulation and characterization of density-driven flow in $\mathrm{CO}_{2}$ storage in saline aquifers. Adv Water Resour 2010;33(4):443-55.

[23] Li D, Jiang X. A numerical study of the impurity effects of nitrogen and sulfur dioxide on the solubility trapping of carbon dioxide geological storage. Appl Energy 2014;128:60-74.

[24] Li D, Jiang X, Meng Q, Xie Q. Numerical analyses of the effects of nitrogen on the dissolution trapping mechanism of carbon dioxide geological storage. Comput Fluids 2015;114:1-11.

[25] Burnol A, Thinon I, Ruffine L, Herri J-M. Influence of impurities (nitrogen and methane) on the $\mathrm{CO}_{2}$ storage capacity as sediment-hosted gas hydrates-Application in the area of the Celtic Sea and the Bay of Biscay. Int J Greenhouse Gas Control 2015;35:96-109.

[26] Erickson KP, Lempp C, Pöllmann H. Geochemical and geomechanical effects of $\mathrm{scCO}_{2}$ and associated impurities on physical and petrophysical properties of Permotriassic Sandstones (Germany): an experimental approach. Environ Earth Sci 2015;74:4719-43.

[27] André L, Azaroual M, Bernstone C, Wittek A. Modeling the geochemical impact of an injection of $\mathrm{CO}_{2}$ and associated reactive impurities $\left(\mathrm{SO}_{2}\right.$ and $\left.\mathrm{O}_{2}\right)$ into a saline reservoir. Transp Porous Med 2015;108:185-205.

[28] Bachu S, Bennion DB. Chromatographic partitioning of impurities contained in a $\mathrm{CO}_{2}$ 
stream injected into a deep saline aquifer: Part 1. Effects of gas composition and in situ conditions. Int J Greenhouse Gas Control 2009;3(4):458-67.

[29] Bachu S, Bennion DB, Pooladi-Darvish M, Hong H. Factors affecting the chromatographic partitioning of $\mathrm{CO}_{2}$ and $\mathrm{H}_{2} \mathrm{~S}$ injected into a water-saturated porous medium. Energy Procedia 2009;1:3165-72.

[30] Bachu S, Pooladi-Darvish M, Hong H. Chromatographic partitioning of impurities $\left(\mathrm{H}_{2} \mathrm{~S}\right)$ contained in a $\mathrm{CO}_{2}$ stream injected into a deep saline aquifer: Part 2. Effects of flow conditions. Int J Greenhouse Gas Control 2009;3(4):468-73.

[31] Pooladi-Darvish M, Hong H, Stocker RK, Bennion B, Theys S, Bachu S. Chromatographic partitioning of $\mathrm{H}_{2} \mathrm{~S}$ and $\mathrm{CO}_{2}$ in acid gas disposal. J Can Petrol Technol 2009;48(10):52-7.

[32] Wei $\mathrm{N}$, Li XC. Numerical studies on the aquifer storage of $\mathrm{CO}_{2}$ containing $\mathrm{N}_{2}$. Energy Procedia 2011;4:4314-22.

[33] Wei N, Li XC, Wang Y, Wang Y, Kong WZ. Numerical study on the field-scale aquifer storage of $\mathrm{CO}_{2}$ containing $\mathrm{N}_{2}$. Energy Procedia 2013;37:3952-9.

[34] Wei N, Li XC, Wang Y, Zhu QL, Liu SN, Liu NZ, et al. Geochemical impact of aquifer storage for impure $\mathrm{CO}_{2}$ containing $\mathrm{O}_{2}$ and $\mathrm{N}_{2}$ : Tongliao field experiment. Appl Energy 2015;145:198-210.

[35] Computer Modelling Group (CMG). User's Guide-GEM: Advanced Compositional Reservoir Simulator. Version 2012. Computer Modelling Group Ltd., Calgary, AB, Canada, 2012.

[36] Li Y, Nghiem LX. Phase equilibria of oil, gas and water/brine mixtures from a cubic equation of state and Henry's law. Canadian J Chem Eng 1986;64(3):486-96.

[37] Peng DY, Robinson DB. A new two-constant equation of state. Ind Eng Chem Fundam 1976;15:59-64 .

[38] Harvey AH. Semiempirical correlation for Henry's constants over large temperature ranges. AIChE J 1996;42(5):1491-4.

[39] Kestin J, Khalifa HE, Correia RJ. Tables of the dynamic and kinematic viscosity of aqueous $\mathrm{NaCl}$ solutions in the temperature range $20-150^{\circ} \mathrm{C}$ and pressure range $0.1-35$ MPa. J Phys Chem Ref Data 1981;10:71-87.

[40] Pedersen KS, Fredenslund A, Christensen PL, Thomassen P. Viscosity of crude oils. Chem Eng Sci 1984;39(6):1011-6.

[41] Rowe AM, Chou JCS. Pressure-volume-temperature-concentration relation of aqueous $\mathrm{NaCl}$ solutions. J Chem Eng Data 1970;15:61-6.

[42] Corey, AT. The interrelation between gas and oil relative permeabilities. Producers Mon 1954;38-41.

[43] Li HL, Jakobsen JP, Wilhelmsen Ø, Yan JY. PVTxy properties of $\mathrm{CO}_{2}$ mixtures relevant for $\mathrm{CO}_{2}$ capture, transport and storage: review of available experimental data and theoretical models. Appl Energy 2011;88:3567-79. 
[44] Li Z, Firoozabadi A. Cubic-plus-association equation of state for water-containing mixtures: is "Cross Association” necessary? AIChE J 2009;55(7):1803-13.

[45] Helmig R. Multiphase flow and transport processes in the subsurface: a contribution to the modeling of hydrosystems. Berlin: Springer; 1997.

[46] Baker RO. Reservoir Management for Waterfloods-Part II. J Can Petrol Technol 1998;37(1):12-7.

[47] Kumar M, Hoang V, Satik C, Rojas D. High-mobility-ratio-waterflood performance prediction: Challenges and new insights. SPE Reserv Eval Eng 2008;11(1):186-96.

[48] Fadairo ASA. Mobility ratio control in water-flooded reservoir with incidence of oilfield scale. Petrol Sci Technol 2010;28(7):712-722.

[49] Gilfillan S, Haszeldine S. Report on Noble Gases, Carbon Stable Isotopes and $\mathrm{HCO}_{3}$ Measurements from the Kerr Quarter and Surrounding Area, Goodwater, Saskatchewan. The Kerr Investigation: Final Report. IPAC CO 2011.

[50] Gilfillan SMV, Wilkinson M, Haszeldine RS, Shipton ZK, Nelson ST, Poreda RJ. He and $\mathrm{Ne}$ as tracers of natural CO2 migration up a fault from a deep reservoir. Int J Greenhouse Gas Control 2011;5:1507-16.

[51] Risk D, Lavoie M, Nickerson N. Using the Kerr investigations at Weyburn to screen geochemical tracers for near-surface detection and attribution of leakage at CCS/EOR sites. Int J Greenhouse Gas Control 2015;35:13-7.

[52] Wells AW, Diehl JR, Bromhal G, Strazisar BR, Wilson TH, White CM. The use of tracers to assess leakage from the sequestration of $\mathrm{CO}_{2}$ in a depleted oil reservoir, New Mexico, USA. Appl Geochem 2007;22(5): 996-1016.

[53] Wells A, Strazisar B, Diehl JR, Veloski, G. Atmospheric tracer monitoring and surface plume development at the ZERT pilot test in Bozeman, Montana, USA. Environ Earth Sci (2010) 60:299-305.

[54] Watson TB, Sullivan T. Feasibility of a Perfluorocarbon tracer based network to support Monitoring, Verification, and Accounting of Sequestered $\mathrm{CO}_{2}$. Environ Sci Technol 2012;46:1692-9.

[55] Humez P, Lions J, Négrel P, Lagneau V. $\mathrm{CO}_{2}$ intrusion in freshwater aquifers: Review of geochemical tracers and monitoring tools, classical uses and innovative approaches. Appl Geochem 2014;46:95-108.

[56] Moni C, Rasse DP. Detection of simulated leaks from geologically stored $\mathrm{CO}_{2}$ with ${ }^{13} \mathrm{C}$ monitoring. Int J Greenhouse Gas Control 2015;26:61-8.

[57] Mayer B, Humez P, Becker V, Dalkhaa C, Rock L, Myrttinen A, etc. Assessing the usefulness of the isotopic composition of $\mathrm{CO}_{2}$ for leakage monitoring at $\mathrm{CO}_{2}$ storage sites: A review. Int J Greenhouse Gas Control 2015;37:46-60. 